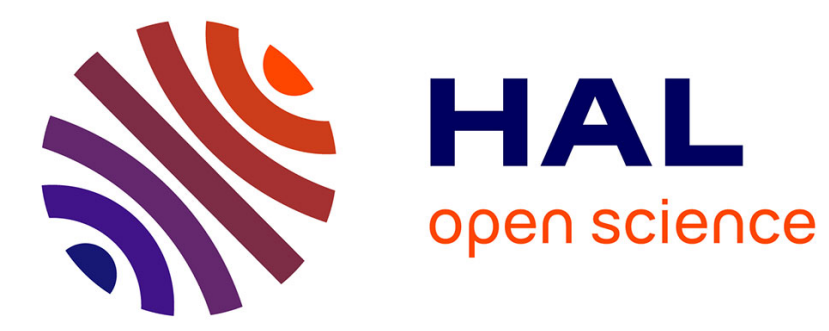

\title{
Effect of drying on the mechanical performances of concrete
}

Farid Benboudjema, François Soleilhet, Xavier Jourdain, Fabrice Gatuingt

\section{To cite this version:}

Farid Benboudjema, François Soleilhet, Xavier Jourdain, Fabrice Gatuingt. Effect of drying on the mechanical performances of concrete. Computational Modelling of Concrete Structures, Euro-C 2018, 2018, Bad Hofgastein, Austria. hal-02153183

\section{HAL Id: hal-02153183 \\ https://hal.science/hal-02153183}

Submitted on 12 Jun 2019

HAL is a multi-disciplinary open access archive for the deposit and dissemination of scientific research documents, whether they are published or not. The documents may come from teaching and research institutions in France or abroad, or from public or private research centers.
L'archive ouverte pluridisciplinaire HAL, est destinée au dépôt et à la diffusion de documents scientifiques de niveau recherche, publiés ou non, émanant des établissements d'enseignement et de recherche français ou étrangers, des laboratoires publics ou privés. 


\title{
Effect of drying on the mechanical performances of concrete
}

\author{
F. Benboudjema \& F. Soleilhet \& X. Jourdain \& F. Gatuingt \\ LMT-Cachan/ENS-Cachan/CNRS/Université Paris Saclay
}

\begin{abstract}
Drying of cement-based materials induces drying shrinkage, which may cause prestress loss or/and cracking if strains are restrained. Due to the slow rate of drying, a strong gradient occurs rapidly leading to tensile stresses at the surface and compressive stresses in the core. Since, drying shrinkage occurs only in cement paste, tensile stresses occur in the cement paste. The prediction of these self-stress state needs the take into account of creep. Besides, capillary pressure, disjoining pressure and surface tension lead to mean compressive stresses in the solid skeleton that can increase the strength of concrete. In order to unveil the contribution of each phenomena, experiments (not presented here) have been carried out on drying, drying shrinkage and mechanical properties after drying or in saturated conditions. Numerical simulations are performed and presented in order to study the effect of drying on mechanical performance of concrete.
\end{abstract}

\section{INTRODUCTION}

Cement-based materials are highly sensitive to water. As soon as the surrounding relative humidity is lower than the one in the material, drying occurs which leads to shrinkage and cracking. Shrinkage is related to the rise of capillary pressure, disjoining pressure and surface energy which creates internal compressive stresses in the solid skeleton. Cracking is due to two mechanisms:

- Differential drying shrinkage between the core and the surface;

- Strain incompatibilities between cement paste (subjected to drying shrinkage) and stiff aggregates.

In parallel, a mean triaxial compressive state of stress in the solid skeleton may increase the mechanical performance of concrete.

A lot of experimental data and models are available concerning drying and induced cracking, but few on the effect of drying on mechanical performance. Regarding the Young's modulus, most authors report a decrease of between 4 and $30 \%$ as concrete dries (e.g. Brooks ad Neville, 1977; Yurtdas et al., 2006). Conversely, there is no consensus concerning the compressive and tensile strengths: regarding compressive strength, some authors report an increase (e.g. Brooks ad Neville, 1977; Yurtdas et al., 2006) while others report a decrease (e.g. Philajavaara, 1974; Hanson, 1968). Concerning tensile strength, a slight increase was found in a splitting test (Hanson, 1968) while an initial decrease followed by a progressive increase up to zero percent relative humidity was observed in bending (e.g. Philajavaara,
1974). A decrease followed by an increase was also measured in direct tensile tests (De Larrard and Bostvirronois, 1991).

Therefore, In order to predict drying shrinkage, induced cracking and effect on mechanical performance, it is important to dispose of a predictive relevant model. The objective of this study is to combine experiments (not presented here, see Soleilhet et al., 2016) and numerical simulation in order to investigate the effect of drying on mechanical performance of concrete.

\section{MODELLING}

\subsection{Drying process}

The drying of cement-based materials is a complex phenomenon. Several, more-or-less coupled, mechanisms are involved: permeation, diffusion, adsorption-desorption and condensation-evaporation. Drying can be analysed through the resolution of liquid water, vapour and dry air mass balance equations. The use of several hypotheses (e.g. Thiery et al., 2007) allows for considering only the mass balance equation of liquid water:

$$
\frac{d S_{l}}{d P_{c}} \frac{d P_{c}}{d t}=\operatorname{div}\left(k_{r l}\left(S_{l}\right) \frac{K}{\mu_{l} \phi} \operatorname{grad}\left(P_{c}\right)\right)
$$

Where $S_{l}, P_{c}, \phi, K, k_{r l}$ and $\mu_{l}$ are, respectively, the saturation degree, the capillary pressure, the porosi- 
ty, the intrinsic permeability, the relative permeability and the viscosity of the liquid water.

It is shown (e.g. Thiery et al., 2007) that this equation is sufficient for an accurate prediction of the drying of ordinary and high-performance concretes at $20^{\circ} \mathrm{C}$ with a relative humidity greater than $50 \%$. The capillary pressure and the relative permeability are related to the degree of saturation through van Genuchten's relation (van Genuchten, 1980):

$S_{l}=\left(1+\frac{P_{c}}{P_{0}}\right)^{1-\gamma}$

$k_{r l}\left(S_{l}\right)=S_{l}^{n k}\left(1-\left(1-S_{l}^{\frac{1}{\beta}}\right)^{\beta}\right)^{2}$

Where nk, $P_{0}$ and $\beta$ are materials parameters.

Depending on the studied sample, the modelling was based on 2D or 3D meshes. Drying at surfaces were modelled using a convection-type approach. In addition, it was found numerically that the evolution of humidity conditions in the climatic chamber did not have a significant impact on the evolution of drying, with respect to the assumption of a constant relative humidity (disregarding hysteresis effects). Therefore it was not taken into account and an average value was used. Finally, an inverse identification tool was implemented to determine $n k, K, P_{0}$ and $\beta$ values thanks to experimental mass lost results.

\subsection{Drying shrinkage}

Following experimental results, the (free) drying shrinkage rate $\dot{\boldsymbol{\varepsilon}}_{d s}$ may be taken as proportional to the water content variation (e.g. Carlson, 1936):

$\underline{\underline{\epsilon}}_{d s}=k_{d s} \dot{w} \underline{\underline{1}}$

Where $k_{d s}$ is a hydrous compressibility factor and $\underline{1}$ is the unit matrix.

It is possible to find alternative approaches but in this present work this modelling approach was chosen. It is easy to implement and give satisfactory results in our case. Moreover, the modelling of the drying shrinkage takes into account basic and drying creep. These allow a relaxation of the stresses decreasing the damage induced by the drying gradients.

\subsection{Basic and drying creep}

The model used for basic creep strain evolution is based on the microprestress theory proposed by Bazant et al. (1997) which has been enhanced in order to predict that basic creep depends on the internal relative humidity (Bazant et al., 1976). This model turns out to be particularly accurate when consider- ing a very long time creep (which is the case here), and is in good accordance with experimental results (cf. the experimental campaign by Brooks (2005) for 30 years creep). The evolution of irreversible creep reads:

$\frac{d \varepsilon_{b c_{-} i}}{d t}=\tilde{\sigma} \frac{\alpha}{t} S_{l}^{n}$

where $\alpha$ is a material parameter. The last right term, depending upon saturation degree, takes into account that the viscosity increases rapidly as drying occurs, leading to a decrease of basic creep strains as previously aforementioned.

In order to reproduce the (partial) reversible part of basic creep, a Kelvin-Voigt chain is used:

$\frac{\tilde{\sigma}}{k}=\varepsilon_{b c_{-} r}+\tau_{K V} \frac{d \varepsilon_{b c_{-} r}}{d t}$

Where $k$ is the stiffness of the spring, $\tau_{K V}$ is the characteristic time of the Kelvin-Voigt chain.

The most used model for (intrinsic) drying creep is probably the stress-induced shrinkage one, proposed by Bažant and Chern (1985), which is based on experimental observations. It has been used in this study:

$\dot{\boldsymbol{\varepsilon}}_{d c}=\mu|\dot{h}| \boldsymbol{\sigma}$

where $\mu$ is a material parameter. Creep is extended to multiaxial state of stress by the use of a creep Poisson ratio, which has been taken equal to the elastic one.

\subsection{Cracking model}

The model is based on the developed by Mazars (1984): a scalar mechanical damage variable is associated to the mechanical degradation process of concrete induced by the development of microcracks. The relationship, between apparent stress $\boldsymbol{\sigma}$, effective stress $\widetilde{\boldsymbol{\sigma}}$, damage $D$ (depending also on tensile strength $f_{t}$ ), elastic stiffness tensor $\mathbf{E}$, elastic strain $\boldsymbol{\varepsilon}_{e}$, creep strain $\boldsymbol{\varepsilon}_{c}$ (sum of basic and drying creep), drying shrinkage $\boldsymbol{\varepsilon}_{d s}$, and total strain $\boldsymbol{\varepsilon}$, reads:

$$
\boldsymbol{\sigma}=(1-D) \widetilde{\boldsymbol{\sigma}} \quad \dot{\tilde{\boldsymbol{\sigma}}}=\mathbf{E} \dot{\boldsymbol{\varepsilon}}_{\mathrm{e}}=\mathbf{E}\left(\dot{\boldsymbol{\varepsilon}}-\dot{\boldsymbol{\varepsilon}}_{\mathrm{c}}-\dot{\boldsymbol{\varepsilon}}_{\mathrm{ds}}\right)
$$

Softening behaviour of concrete may lead to nonunity of solutions and mesh dependency. Energetic regularization prevents these difficulties and has been used here (Hillerborg. et al., 1976).

Finally, a random field on the tensile strength generated by the Turning Band Method (Matheron, 1976) is used in order to take into account the variability of the material. The chosen parameters are:

- A variation coefficient equal to $10 \%$;

- A correlation length taken three times bigger than the biggest aggregate. 


\subsection{Calculation of crack openings}

To get crack openings, models rely on two main classes of techniques. Either post process cracks of a continuous damage field (Matallah and La Borderie, 2010) or the use of discontinuous models (XFEM, discrete or cohesive elements for instance). As part of this work, a post cracking method based on the damage field of the continuous model presented in the previous section, taking into account delayed deformations was used.
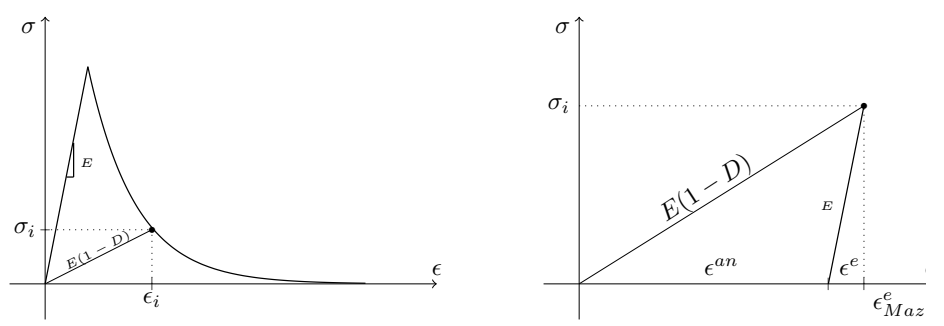

Figure 1. Uniaxial tension test schematic representation.

We can consider a strain partition as it is developed in (8) with $\epsilon_{\operatorname{Maz}}^{\mathrm{E}}$ the mechanical strain given by the Mazars' model (see Figure 1).

$\epsilon_{\mathrm{ii}}=\epsilon_{\mathrm{Maz}}^{e}+\epsilon_{\mathrm{kl}}^{\text {drying }}+\epsilon_{\mathrm{kl}}^{\text {creep }}+\cdots$

This total mechanical strains is given by the equation (9) coming from equation (5):

$\epsilon_{\text {Maz }}^{e}=\left((1-D) C_{i i k l}\right)^{-1} \sigma_{i i}$

With $\mathrm{D}$ the damage, $\mathrm{C}_{\mathrm{ijk}}$ the stiffness matrix and $\sigma_{i j}$ the strength. We can easily find the elastic strain, which is link to the strength by the stiffness matrix (equation (10)). We can make the assumption that the total strains can be divided into two parts. An "elastic" part and an other "inelastic".

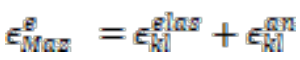

It is thus possible to calculate the various strains necessary for the quantification of the crack opening. The "elastic" strains is given by (11) while the "inelastic" strains is given as the difference between the total deformation field and the "elastic" deformation field (12).

$\epsilon_{k i[}^{\text {elas }}=C_{i i k l}^{-1} \sigma_{i i}$

$\epsilon_{\mathrm{k} l}^{\text {ane }}=\epsilon_{\text {Maz }}^{e}-\epsilon_{\mathrm{ki}}^{\text {elas }}$

Final the crack opening is the product of the strains times the size of the element.

$U_{k}=\epsilon_{k i}^{\text {ane }} \cdot h_{l}$

\section{NUMERICAL SIMULATIONS}

The results presented in this section tend to simulate the behaviour of $10 \times 10 \times 84 \mathrm{~cm}$ specimens tested in three point bending. They were kept under drying conditions $\left(50 \% \mathrm{RH}\right.$ under a temperature of $\left.21^{\circ} \mathrm{C}\right)$ for 70 days before testing. Parallel to this, other test pieces (similar in terms of geometry as well as concrete used) are kept in wet conditions. The results are then compared to characterize the impact of drying.

\subsection{Drying process}

The specimens' drying conditions (i.e. 50\% RH) allow to only take into account the permeation in the modelling process. After an identification of the drying parameters by an inverse method based on the mass loss curves, the specimens are characterized with respect to the drying. The experimental mass losses as well as the gradients within the test pieces are obtained.

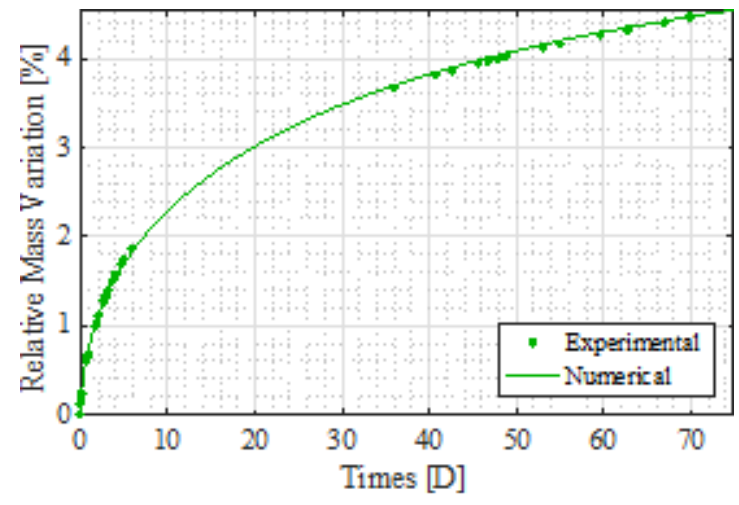

Figure 2. Evolution of Relative Mass Variation

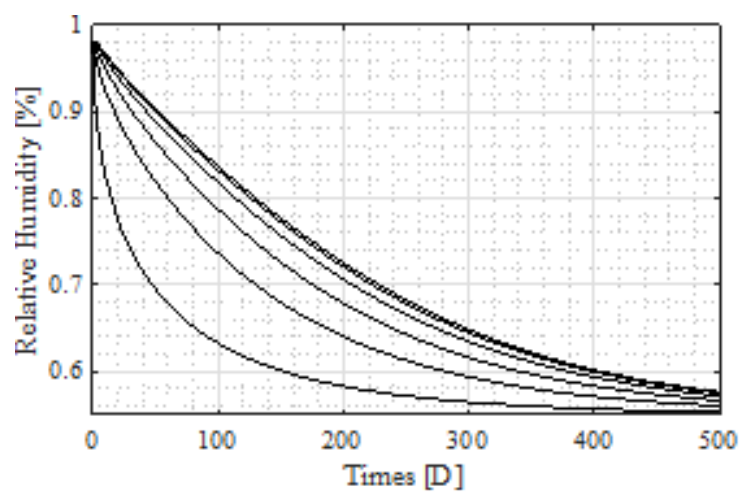

Figure 3. Evolution of RH gradient along the sample thickness

The relative mass variation is well predicted (figure (2)). The gradient of moisture within the test piece (figure 3) is strong in the first moments and then tends to decrease over time. This difference between the core of the sample and the edge will therefore generate differential strains which will induce microcracking. In addition, a structural effect will be brought about by the non-homogeneity of the con- 
crete with respect to moisture. This difference will generate additional resistance

\subsection{Drying shrinkage}

Phenomenological modelling of the drying shrinkage is based on the determination of water content gradients. The latter are obtained from the moisture gradients determined by the modelling of the drying process. Thus, the drying shrinkage and the state of internal stresses generated are obtained.

The drying shrinkage is calibrated on $7 \times 7 \times 28 \mathrm{~cm}$ specimens. The phenomenological model can correctly predict the evolution of drying (figure 4). The final value is consistent, nevertheless the initial part at the short term seems wrongly predicted. This is mainly due to the mistake made in the prediction of drying. Indeed, the short-term behaviour is strongly impacted by the boundary conditions, difficult to characterize and rather variable depending on the case

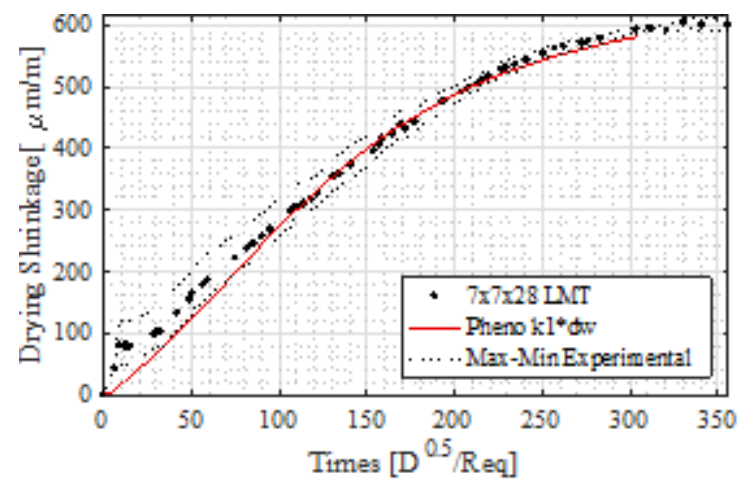

Figure 4. Evolution of drying shrinkage

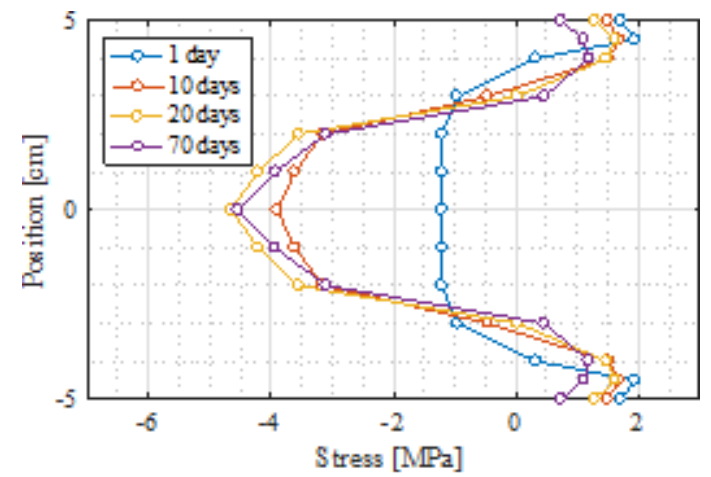

Figure 5. Evolution of normal stress along the center line

If one is interested in the state of initial stresses (figure 5), in the short term (1 day), tensile areas on the edge of the sample appear. The stresses are strong initially then the areas impacted by tension are damaged and the stress decreases in the short time. As time goes by, the thickness impacted by drying increases and the compressive stress at the centre tends to increase. The internal stresses imposed on the mechanical model correspond to the state of stress after 70 days. The section is visibly not at equilibrium.

\subsection{Effect of drying on the mechanical properties in bending}

Finally, the mechanical modelling is divided into two parts. It is started by the identification of the models parameters on wet beams' experimental curves and followed by the modelling of the drying process on similar beams exposed to drying.

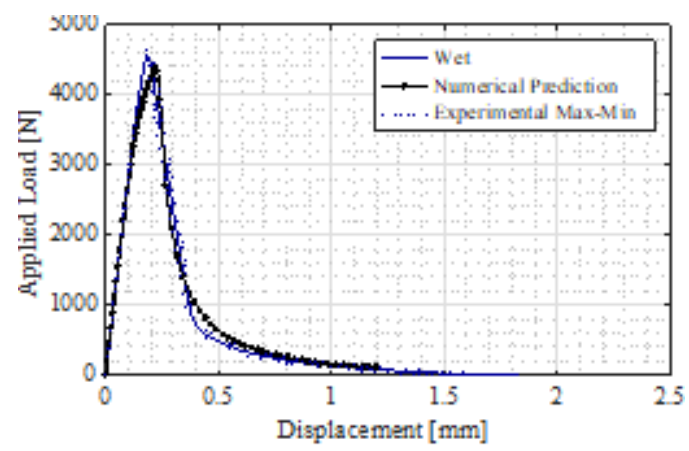

Figure 6. Calibration of model parameters in bending test (no drying)

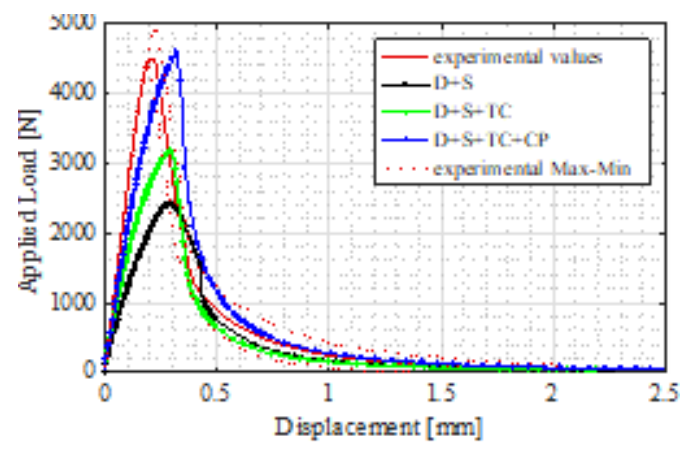

Figure 7. Prediction of the behaviour in bending after drying

It is shown in figure 7 that taking into account the state of initial stresses due to drying strongly influences the macroscopic behaviour. If only drying shrinkage $(D+S)$ is taken into account, the resulting damage is overestimated. Non-linearities appear very quickly, decreasing stiffness as well as peak strength. However this state is not representative of the phenomenon, the creep will reduce the stresses within the sample and at the same time reduce the damage, which will give a stronger behaviour (D + $\mathrm{S}+\mathrm{TC}$ ). Finally, within the material, the desaturation of the pores will lead to capillary phenomenon, which will lead to an increase in the overall strength. The case $(\mathrm{D}+\mathrm{S}+\mathrm{TC}+\mathrm{CP})$ takes this phenomenon into account. The overall behaviour appears to be better represented, however, an underestimation of the initial stiffness is still observed.

To illustrate the crack opening routine based on post-processing the damage, one can look at the cracking map obtained after 70 days of desiccation 
(figure 6). There are no other stresses than those imposed by drying
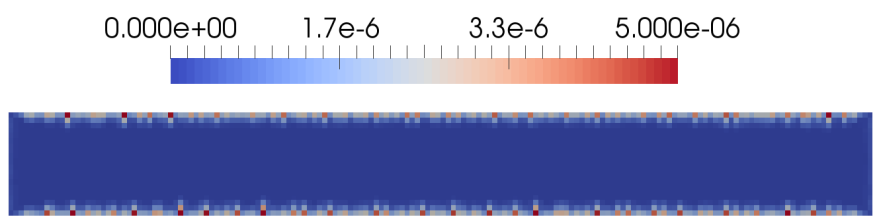

Figure 8. Crack map due to drying shrinkage [m]

With regard to the distribution of the cracks, it is noted that they are distributed around the circumference of the sample. This is easily justified by the fact that these areas are most affected by the hydric gradient. As for the size of the openings, they do not exceed the order of ten micrometres. This cracking is diffuse on the edges of the specimen nevertheless it remains superficial

\section{CONCLUSION}

The drying phenomenon of cementitious materials is a major importance for understanding and forecasting long-term behaviour. Whether in terms of mechanical strength, behaviour (more or less brittle) or even transfer (fluid flux by permeation evolved with the cube of the crack opening), an impact of drying is observed experimentally. Although relative to all structures, drying is not much studied. The results found in the literature are sometimes inconsistent but can be explained by the different phenomena involved. Indeed, in the process three main phenomenon can be distinguished. The capillary pressure which stiffens the structure, the microcracking induced by the gradient of moisture and finally the strains incompatibilities.

The numerical approach presented in this paper is based on a four steps procedure which is concerned firstly with characterizing the water state of the material. This subsequently allows to quantify the delayed strains in order to then assume the internal state of stresses generated by drying shrinkage. These stresses are then took as initial value of the mechanical computation to finally obtain cracking pattern. They can be characterized regarding transfer phenomena by a external model not presented in this paper. The results presented here show that, as experimentally, the drying behaviour is strongly impacted by the drying shrinkage. Nevertheless, taking into account the phenomenon of capillary pressure and creep make it possible to approach a more realistic behaviour. In the modelling protocol there is no regard concerning strains incompatibilities. Some authors have proposed model to take this phenomenon into account but it is not widespread and it is still difficult to calibrate models' parameters.
Finally, the model presented allows to simulate the behaviour of large structure under drying from the hydric characterization to the hydric transfer. And it has the advantage on relying on a model regularize in fracture energy which makes it suitable for large scale modelling.

\section{REFERENCES}

Bažant Z.P., Asghari A., Scamiot J. 1976 Materials and Structures 9: 279-290

Bažant Z. P., Chern J. C., 1985 Materials and Structures 18:1-20

Bažant Z.P., Hauggaaed A.B., Baweja S., Ulm F.J., Journal of Engineering Mechanics 123:1188-1194

Brooks JJ, Neville AM. 1977 A comparison of creep, elasticity and strength of concrete in tension and in compression. Magazine of Concrete Research 29(100):131-141.

J. J. Brooks 2005 Magazine of concrete research 57:545-556

Carlson, RW. 1937 Drying shrinkage of large concrete members. $J$ of the Am Concrete Inst;33:327-336.

De Larrard F, Bostvirronois JL. 1991 On the long term losses of silica fume high strength concretes. Magazine of Concrete Research 43(155): 124-129.

Hanson JA. 1968 Effects of curing and drying environments on splitting tensile strength of concrete. Journal of the American Concrete Institute 65(7):535-543.

Hillerborg A, Modéer M, Petersson P-E. 1976 Analysis of crack formation and crack growth in concrete by means of fracture mechanics and finite elements. Cem Concr Res 6:773-81

Matallah, M., La Borderie, C. 2010 A practical method to estimate crack openings in concrete structures. International Journal for Numerical and Analytical Methods in Geomechanics 34:1615--1633

Matheron, G. 1973 The intrinsic random functions and their applications. Advances in applied probability:439--468,

Mazars, J. 1984. Application de la mécanique de l'endommagement au comportement non linéaire et à la rupture de béton de structure, Thèse de doctorat d'état, $\mathrm{Pa}-$ ris VI.

Philajavaara SE. 1974 A review of some of the main results of a research on the aging phenomena of concrete: effect of moisture conditions on strength, Shrinkage and creep of mature concrete. Cement and Concrete Research 4(5):761771.

Soleilhet, F., Benboudjema F., Jourdain X, Gatuingt F. 2016 Experimental and numerical investigation of drying effects on concrete's mechanical properties in International RILEM Conference on Materials, Systems and Structures in Civil Engineering

Thiery, M., Baroghel-Bouny 2007 Modélisation du séchage des bétons : analyse des différents modes de transfert hydrique. Revue Européenne de Génie Civil 11:541--577

van Genuchten M Th. 1980 A closed-form equation for predicting the hydraulic conductivity of unsaturated soils. Soil Science Society of America 44:892-898

Yurtdas I, Peng H, Burlion N, Skoczylas F. 2006 Influences of water by cement ratio on mechanical properties of mortars submitted to drying. Cement and Concrete Research $36: 1286-1293$. 